\title{
Quantifying Psychosocial Impacts From Coastal Hazards for Cost-Benefit Analysis in Eastern Quebec, Canada
}

\author{
Ursule Boyer-Villemaire ${ }^{1,2 *}$, Cicéron Vignon Kanli ${ }^{1,3}$, Guillaume Ledoux ${ }^{1,4}$, \\ Charles-Antoine Gosselin ${ }^{2,5,6}$ and Sébastien Templier ${ }^{1,3}$
}

${ }^{1}$ Réseau Inondations Intersectoriel du Québec and Consortium ÉGIDE, Département de géographie, Université du Québec à Montréal, Montréal, QC, Canada, ${ }^{2}$ Ouranos, Montréal, QC, Canada, ${ }^{3}$ CIUSSS du Centre-Sud-de-l'Île-de-Montrèal, Montreal, QC, Canada, ${ }^{4}$ Fire Security and Public Safety Department, City of Trois-Rivières, Trois-Rivières, QC, Canada, ${ }^{5}$ WSP Canada (Environment), Quebec, QC, Canada, ${ }^{6} \mathrm{HEC}$ Montreal, Montreal, QC, Canada

OPEN ACCESS

Edited by:

Scott Bremer,

University of Bergen, Norway

Reviewed by:

Meaghan E. Daly,

University of New England,

United States

Tiago Capela Lourenço,

University of Lisbon, Portugal

${ }^{*}$ Correspondence:

Ursule Boyer-Villemaire boyer-villemaire.ursule@ouranos.ca; boyer-villemaire.ursule@uqam.ca

Specialty section:

This article was submitted to

Climate Risk Management,

a section of the journal

Frontiers in Climate

Received: 04 August 2020 Accepted: 02 June 2021 Published: 14 July 2021

Citation:

Boyer-Villemaire $U$, Kanli $C V$,

Ledoux G, Gosselin C-A and

Templier S (2021) Quantifying Psychosocial Impacts From Coastal Hazards for Cost-Benefit Analysis in

Eastern Quebec, Canada.

Front. Clim. 3:591416.

doi: 10.3389/fclim.2021.591416
The assessment of psychosocial impacts related to coastal hazards (erosion, submersion) has so far been mainly qualitative. As cost-benefit analysis is gaining popularity among communities to assess adaptation options in the face of increasing coastal hazards, there is a need to develop quantitative indicators to improve the inclusion of human impacts in decision-making. The project therefore aimed to suggest quantitative indicators for a cost-benefit analysis in the Lower St. Lawrence region exposed to the waters of the estuary of the St. Lawrence River in eastern Quebec, Canada. A systematic survey of five municipalities was conducted in 2019 ( $n=101)$. In general, the prevalence of mental health impacts was the double than that of physical health (30 vs. 14\%); and was higher for affected respondents: 50.0 and $23.9 \%$, against 13.5 and $5.8 \%$ for unaffected respondents.

With regards to psychosocial impacts, the main results were that

(i) affected people were 2.33 more stressed in normal times than unaffected respondents and this variation increased to 3.54 during a storm surge warning;

(ii) the quality of sleep of affected respondents when a storm warning is issued was 2.39 poorer than that of unaffected respondents.

With regards with economic impacts,

(i) an additional $11 \%$ in absenteeism has been observed among respondents affected;

(ii) the likelihood of experiencing financial difficulties was 1.27 higher for those affected;

(iii) a small subgroup of affected respondents $(<10)$ declared a mean of 400 CAD of additional health expenses.

The results show that the assistance received provides little protection against stress, or even increases it, if it is mainly financial. In addition, a high degree of social isolation and living alone increases stress in the face of hazards. Thus, social capital and psychosocial assistance act as a protective factor in reducing psychosocial impacts. The probability of financial stress, on the other hand, increases in the event of maladaptation (inefficient adaptation expenditures leading to repair costs). Overall, the importance of the impacts measured justifies further economical investigation for their inclusion in the cost-benefit analysis.

Keywords: psychosocial impacts, coastal erosion, flooding, public health, cost-benefit 


\section{HIGHLIGHTS}

- The prevalence of declared mental health issues due to coastal hazards was the double than that of physical health issues (30\% vs. 14\%); and higher for affected compared to unaffected respondents.

- In normal times, respondents affected by coastal hazards were 2.34 times more stressed than those unaffected by them, and in times of storm, the warnings induced 3.54 more stress to those affected than those unaffected.

- Respondents affected by coastal hazards experience 2.39 times more sleep disturbance during a storm event than those unaffected.

- Other indicators measured are of a social (assistance received and social isolation) and economic (loss of productivity, financial hardship, additional health expenses) nature.

\section{INTRODUCTION}

In flood and shoreline erosion risk management, cost-benefit analysis (CBA) is the economic comparison of all direct and indirect benefits and costs of different technically feasible adaptation or mitigation options (Penning-Rowsell et al., 2013, Circé et al., 2016). These analyses make it possible to determine priority areas or intervention strategies, identify the most appropriate adaptation measures and justify the investments associated with coastal management. Best practices include considering psychosocial impacts in cost-benefit analyses (Penning-Rowsell et al., 2013).

However, the literature presents few epidemiological studies on such impacts and even fewer from an economic standpoint. Indeed, the psychosocial impacts of disasters have been described from the standpoint of mental health signs and symptoms (Bolin, 1985; Leon, 2004), of the delay between the stressor and its onset (Adams and Boscarino, 2006) and of the intervention and its importance in the recovery phase (Reyes and Elhai, 2004; Dückers et al., 2017). However, case studies abound for various types of hazards around the world (e.g., forest fires: Kulig and Dabravolskaj, 2020; oil spills: Gill et al., 2016; nuclear accidents: Midorikawa et al., 2017; train derailments: Généreux et al., 2019, Maltais et al., 2019; floods: Johal and Mounsey, 2016). The first reviews of such literature (e.g., Korman et al., 2019) indicate that the subject has attained a certain maturity. However, there is a lack of quantitative data on psychosocial impacts, which directly limits its integration into CBA. That said, a coconstruction approach with municipalities in eastern Quebec, Canada provided the context for filling this gap. The purpose of this paper is therefore to present the results of a quantification of the psychosocial impacts of flooding and coastal erosion with a view to their integration into a CBA of adaptation options at the municipal level.

\section{LITERATURE REVIEW}

\section{Natural Disasters}

The risk of natural, weather and climate-related disasters is increasing exponentially worldwide (CRED, 2018), as it has in Canada since the 1960s (Etkin et al., 2010). As a result, the number of storms and flood hazards is increasing (CRED, 2018). Floods accounted for $79 \%$ of the total number of natural disasters worldwide between 1970 and 2012, or 54\% of deaths and $84 \%$ of total economic losses over the same period (WMO, 2014). The Sendai Framework for Disaster Risk Reduction 20152030 therefore indicates the need for action on prevention, management and reduction of risks in the run-up to disasters, as well as on building resilience. The Framework calls for a substantial reduction in disaster risk and its consequences affecting lives, livelihoods and health (UNISDR, 2015). The increase in various hazards has unprecedented social, human and economic consequences (IPCC, 2012; WMO, 2014; CRED, 2018). The Intergovernmental Panel on Climate Change (IPCC) states that the dangers associated with climate extremes-the triggers of natural disasters-affect people living in poverty more so than others (IPCC, 2012). For example, $89 \%$ of storm-related deaths occur in low-income countries, even though low-income countries have experienced only $26 \%$ of all storms (CRED, 2018). From an economic perspective, between 1998 and 2017, disasters caused annual losses of US $\$ 2.9$ billion worldwide, $77 \%$ of which were climate-related (CRED, 2018). Reducing these human and material losses substantially is a global priority. To this end, the Sendai Framework for Disaster Risk Reduction 2015-2030 identifies the need to address prevention, management and reduction of risk in the run-up to a disaster, as well as building resilience (UNISDR, 2015).

These figures indicate that accounting for the consequences of these disasters is generally reflected in indicators of death and damage to physical assets. However, disaster reduction requires decision-making based on wider scope of impacts in order to maintain the quality of life of communities, in a sustainable development perspective. The psychosocial and health impacts of coastal hazards occur after the event (Bond, 2018), yet knowledge about how to anticipate these hazards and impacts is scarce.

\section{Health and Psychosocial Impacts of Coastal Hazards Assessment}

There is a recently growing canon of literature pertaining to the health and psychosocial impacts of natural hazards (Korman et al., 2019). The extent and degree of these impacts are characterized by associated mental health problems, such as the development of post-traumatic stress disorders (PTSD) and anxiety and depressive disorders (Alderman et al., 2012). The various stresses experienced during and after a disaster can additionally lead to emotional shock, fear, anger, irritability, sadness (Maltais, 2003; Priebe et al., 2011; Maltais and Gauthier, 2013) and sleep disturbance (Meewisse et al., 2005). Coherently, the secondary stressors of flood (being concerned about health, problems with relationships and loss of sentimental items) trigger a probability of psychological morbidity (Tempest et al., 2017).

These impacts are characterized by a delayed and/or persistent time signature. Indeed, consequences related to psychological well-being (physical or health consequences, emotional or psychological consequences) often take longer to resolve than financial repercussions and material loss, even up to 5 years 
(Verger et al., 2003; Ibrahim, 2016). This loss and the appearance (or worsening) of physical ailments can create long-term psychological consequences: links have been made between this and negative self-reported health indices, increased use of outpatient medical services, excessive use of medications, alcohol, drugs and cigarettes, as well as household conflict and stress (Maltais et al., 2001).

\section{Relationship Between Vulnerability and Coping Capacity}

At the origin of the health and psychosocial impacts of disasters are both the manifestations of the hazard itself (probability and exposure), as well as the vulnerability of the exposed community (Alderman et al., 2012). Vulnerability is a foundation concept widely studied in environmental hazards and climate change contexts during the last two decades (e.g., Turner et al., 2003; Almedom, 2005; Adger, 2006; Smit and Wandel, 2006). Even though its applicability has been questioned, it remains a valid concept for empirical research and catalyzing collaboration across disciplines (Ford et al., 2018). The diverse factors of vulnerability may arise from the studied system or from extrinsic drivers, or be biophysical (hazard or territory related) or socioeconomic (tangible or perceived) (Füssel, 2007). In this article, we based our interpretation of vulnerability according to Watts and Bolhe (2013), that refer to exposure (to the hazard), ability (to cope with the crisis) and potentiality (to recover from losses incurred), because it includes the potential system's evolution and is thus less static (Ford et al., 2018).

From a public health perspective of psychosocial impact of hazards, socioeconomic vulnerability is crucial for coping capacity and potential to recover. Groups are classified vulnerable based on a span of characteristics, from socioeconomically intrinsic (such as the elderly, single mothers, people with disabilities and low-income families) to extrinsic health related factors (ex. under five mortality ratio, hospital bed ratio, access to MCV1 and DTP3 vaccines) (Chan et al., 2019). They are less likely to receive the appropriate services that would help them cope; these groups are also more likely to experience post-disaster health problems (Norris et al., 2002).

This is notably because many in these already vulnerable groups depend on others to relocate or protect themselves against disasters, and have difficulty accessing the available community resources (Maltais and Gauthier, 2013). It is the resilience of communities themselves that makes it possible for these groups to overcome, to a certain extent, this vulnerability and develop coping capacity and potentiality to recover from losses.

\section{Social Capital and Individual Coping Capacity}

The strength of community resilience is measured by leadership, readiness to act, collective effectiveness, trust and dedication to place (Greene et al., 2015).

In these cases, the community takes on the role of a collective actor-social capital and networks are essential in both survival and post-disaster recovery (Chaskin, 2008; Rapaport et al., 2018). Bourdieu (1980) presents the social capital as an ensemble of actual or tangible resources that provide permanent and useful relationships to agents, a sustainable resource that cannot be simply decomposed into geographic or socioeconomic drivers. The social capital in climate change context builds over two essential components (Adger, 2001): (1) the bonding refers to the strength of relationships among a group of actors and is important for low income and socially excluded groups, when State provides social security; (2) the bridging defines as the level of "liaison" among various groups, and reveals its importance in contexts of dynamic mobile communities, management of collective resources and in the absence of State support. Brisson and Richardson (2009) evoke the need for community solidarity as a solution to "get through" a crisis and reduce feelings of vulnerability. Although investments in physical infrastructure are often the first steps taken to deal with natural hazards, it is social infrastructure that promotes and strengthens community resilience (Aldrich and Meyer, 2015). Criticality remains important for its implementation, as among the main pitfalls identified lies the danger of community tensions, notably through power plays (Pelling and High, 2005). At the scale of individual coping capacity, social capital acts as a support to mental health and the other way around (treatment of mental disorders improves social capital) (Sartorius, 2003). Therefore, Aldrich and Meyer (2015) suggested that social infrastructureand solidarity-is a critical infrastructure that should be included as an essential aspect of effective disaster recovery.

\section{Gap in Psychosocial Impacts of Coastal Hazards}

One under-researched area in the academic field are the health and psychosocial impacts of coastal hazards (Brisson and Richardson, 2009). However, this topic is of growing interest, notably as the impacts of coastal storms increase in frequency and intensity. Indeed, at the time of writing, at least two projects on this topic are being conducted in the province of Quebec alone, the first aiming to improve the disaster response of healthcare services (Brisson and Lessard, 2018), and the second as an epidemiological survey of communities exposed to the historic floods of 2017 and 2019 (Genereux et al., 2017).

Coastal erosion alters the capacities and well-being of the people it affects (Brisson and Richardson, 2009). Indeed, erosion damages property as well as the sense of well-being and identity; it degrades not only a monetary investment but also affects the "home," a place of experiences, memories and a source of emotion and material well-being. In other words, the ontological security of the individual and household itself is degraded (Dupuis and Thorns, 1998). Additionally, the potential loss of the home causes stress and anxiety compounded by the impact of witnessing the progression of erosion, jeopardizing one's security and one's home. This anxiety can turn into "panic" for people who live on cliff edges as they witness their land eroding (Brisson and Richardson, 2009).

These findings reveal that the health repercussions of disasters generate costs both for the impacted individual and for society. In the decision to invest in adaptation, these costs must be tallied and analyzed. Coherently with the literature cited above, Verger et al. (2003) explored cumulative indicators of PTSD due to floods. Property damage appeared the main factor, compared to physical presence on site, effect on work, previous exposure to endangerment situation, assistance received during the event, 
evacuation and, to a lesser extent, the loss of pets. However, to our knowledge, the only methodology of economic quantification of psychosocial impacts can be found in the United Kingdom and its major floods of the year 2000. During this time, the National Science Agency found itself under tremendous pressure created by the visible psychological impacts which the flooding had on its employees. The economic cost to the agency associated with higher than usual rates of absenteeism was a particularly useful case study to measure the human costs of flooding on response teams (Penning-Rowsell et al., 2013). For coastal erosion, however, this financial impact has not been well-documented. This project, therefore, aims to quantify the cumulative psychosocial impacts of coastal hazards (erosion and flooding) in order to glean indicators for cost-benefit analyses of adaptation measures in these contexts.

\section{THE STUDY SITE: QUEBEC, CANADA}

\section{Hazards and Issues at Stake}

In the province of Quebec, Canada, there has been an average of more than one major flood per year for the past 25 years and their recurrence is increasing in the context of climate change (INSPQ, 2015). While the results of the major floods in 2017 were disastrous (261 municipalities and 5,371 homes affected, 4,066 people evacuated) (Urgence Québec, 2017), those of the floods in 2019 were historic: 310 municipalities affected, 5,448 homes flooded, 10,386 people evacuated, 3,889 residences isolated, at one of the strongest moments of the crisis (Ministère de la Sécurité Publique, 2019). These events, along with the LacMégantic derailment, explain the strong interest in mental health in disaster situations in Quebec.

Nevertheless, river flooding is not the only hazard in Quebec. Coastal erosion and coastal flooding, already quite extensive and expanding throughout the St. Lawrence River estuary, are hazards that generate potentially permanent impacts on the environment and communities (Bernatchez et al., 2015). The intensity of coastal flooding depends on water levels and waves breaking on the coast (Bernatchez et al., 2015). This hazard tends to increase in eastern Canada, due to several factors. Sea level rise resulting from global sea level rise and isostatic adjustment in the estuary (continental subsidence) cause a rise in relative sea level for the southern part of the maritime sector and the Gulf of St. Lawrence (Koohzare et al., 2008; James et al., 2014; Han et al., 2015). In addition, there is a decrease in ice cover, which reduces the period, area and thickness of ice contributing to the lengthening of the annual wave period (Bernatchez et al., 2015) and a change in the storm regime (Natural Resources Canada, 2016).

Historically, the occupation of Quebec territory developed along the St. Lawrence seaway without giving much consideration to coastal dynamics and risks. The communities of the St. Lawrence estuary, from the mouth of the Saguenay River to the Magdalen Islands archipelago, including the Lower St. Lawrence, Gaspé and North Shore regions, have been hit by major maritime storms over the past 10 years: the storm of December 2010 with its historic rain and waves from the Côte-Nord of the Gaspé Peninsula; the rain, waves and strong winds of the winter storm of 2016; the storm of fall 2018 that cut off the Magdalen Islands from all communication with the continent for $24 \mathrm{~h}$; and the passage of the tail-end of Hurricane Dorian in September 2019, which left significant damage on the eastern coast of the Gaspé Peninsula in its wake. In these regions of Quebec, a total of nearly 400,000 people are potentially affected by the harmful effects of these hazards on the coasts (Statistics Canada, 2016). The totality of assets at risk of coastal erosion over 50 years (buildings, roads, railways) is assessed at CAD 1.5 billion (2015 dollars) (Bernatchez et al., 2015). The financial capacity to cope is therefore of particular concern.

In the Lower St. Lawrence administrative region of Quebec, the Mitis and Rivèire-du-Loup regional county municipalities (RCMs) account for rather small populations: 18,210 people (8,205 households) and 33,958 people (15,155 households), respectively, according to the latest census (Statistics Canada, 2016). However, they face rather important exposure, as Bernatchez et al. (2015) estimated that by 2,065 a total of 351 residential buildings will have been exposed to coastal erosion on the territory of the RCM of Mitis, and 332 on the territory of the RCM of Rivière-du-Loup. Restoration and recovery costs (debris removal, reconstruction, etc.) have direct impacts on communities (Bernatchez et al., 2015). These come in addition to the costs of economic, environmental and psychosocial impacts, as well as the costs of increased episodes of damaging flooding.

In the case of maritime infrastructures installed on low coasts (e.g., soft sediment terraces, spits, sea marshes) or on soft sediment cliffs that are particularly vulnerable to hazards, it is noted that rigid protection infrastructures (riprap, concrete dykes) do not have the expected effect and even aggravate the effects of storms (Bernatchez et al., 2011). Indeed, rigid protection keeps sand away from the coast, lowers the levels of beaches and contributes to beach erosion. Thus, while climate change increases the probability and intensity of hazards, the absorption capacity of coasts decreases and vulnerability (population exposure) increases (Bernatchez and Quintin, 2016). In this context, it is necessary to integrate the creation of buffer zones and open spaces into land-use planning to reduce the exposure of populations and infrastructures in at-risk areas (Buffin-Bélanger et al., 2015; Bernatchez and Quintin, 2016), in order to ensure the long-term resilience of Quebec's coastal municipalities.

\section{The Co-construction Approach}

To support the adaptation of coastal management in Quebec, the Ouranos research consortium first conducted 25 cost-benefit analyses (CBAs) of coastal adaptation options in five regions struggling with these issues (Circé et al., 2016), in partnership with local communities and using the most recent coastal hazard analyses (Boyer-Villemaire et al., 2016). The subsequent phase aimed to systematize and transfer technical capacity for economic analysis from the research community to local practitioners and decision-makers responsible for land use planning and risk management. Thus, an operational, integrative and simple computer tool for conducting economic analyses of coastal adaptation options was developed: the Platform for Benefit-Cost Analysis of Erosion and Submersion (PANACÉES). 
However, in the feedback on the first phase of the 2014-2016 CBAs, the communities expressed their concerns about the lack of integration of psychosocial impacts in the process (note: no overlap between the participants and the survey respondents of this paper). The lack of knowledge had so far limited their integration. In fact, in Quebec and around the world, although projects have looked at psychosocial impacts and major risks (e.g., Généreux et al., 2019; Maltais et al., 2019), little data of this type remains available to integrate these impacts into a quantitative CBA-type analysis.

The approach outlined here was therefore aimed at quantifying the psychosocial impacts on the PANACÉES project study sites, comprised of the six municipalities making up the RCMs of La Mitis (Grand-Métis, Métis-sur-Mer, SainteLuce, Sainte-Flavie) and Rivière-du-Loup (Rivière-du-Loup and Notre-Dame-du-Portage). The local follow-up committee chose to exclude the municipality of Ste-Flavie because of an over-solicitation of citizens to participate in studies on coastal issues over the past decade. Thus, five municipalities are under study, and these have suffered damages to varying degrees, including from the major storm of December 6, 2010. However, on the whole, the municipalities of the RCM de la Mitis were more at risk, particularly Sainte-Luce and Sainte-Flavie, due to the absence of cliffs and the greater proximity of the hearts of the villages to the coast. The anticipated outcomes are the selection and quantification of economic impact indicators related to mental health that could improve the CBAs and the PANACÉES tool.

\section{METHODOLOGY}

\section{Survey}

The methodological approach is based on a sample survey of the citizens of the five selected municipalities. The approach has obtained ethical certification from UQÀM (UQÀM certificate - CERPE FSH 3479). The team developed a questionnaire aimed at (1) quantifying the diversity of the psychosocial impacts of coastal hazards within a given population (to evaluate the proportion of certain indicators rather than diagnose specific health impacts) and (2) measuring the economic consequences of psychosocial impacts, and (3) assess explanatory variables, including vulnerability and social capital. The survey (see Appendix 1) was designed in co-construction with a monitoring committee (geographers, economists, professionals, and local elected officials). After a review of the literature, the essential concerns and indicators were validated with partnering local authorities (municipalities, RCMs and some regional departments) in order to develop the questions. The potential indicators selected included: overall impacts on physical and mental health, stress and sleep disruption; burden of expenses associated with health impacts; cost of preventive measures; contribution to the recovery effort; and financial difficulties. In addition to traditional socio-demographic descriptors (e.g., age, gender, education, income), hazard experience, degree of exposure, effect of early warnings, help received and degree of isolation were also assessed. Questions were "closed" (yes or no) or "open" (yes or no followed by an explanation), multiple choice, intensity scale (ordinal, $0-10$ ) or descriptive.

To build the sample required for the survey, La Mitis and Rivière-du-Loup provided an initial pool of 683 households spread across their five municipalities and exposed to the hazards of coastal flooding and coastal erosion over a horizon up to 2100. In the absence of public flooding data, the erosion risk zones were delineated by projections of the rate of coastline mobility up to the year 2100 produced by the Laboratoire de dynamique et de gestion intégrée des zones côtières (LDGIZC, 2017) of the Université du Québec à Rimouski (UQÀR). This pool corresponds to the total population that can be potentially affected by coastal hazards, over the 23,000 households of the two RCMs. Using a random allocation technique, the households were numbered and the first 100 were sent a solicitation notice by mail. The study was also publicly advised on the websites of the participating municipalities. The refusals were replaced with subsequent numbers, with a target to obtain a minimum 100 sample-size (selected according to scientific rigor, time and resources allocated for data collection).

The door-to-door survey collected testimonials from 101 households. One person per household was interviewed for 15$30 \mathrm{~min}$, at his or her home or at a location of his or her choice. All respondents were of legal age. The survey was conducted in three phases in 2019: May 11-25, September 9-21, and December 5-17. No major coastal events were recorded during this period.

Because of the high emotional charge of the subject of the potential relocation of certain households, three main risk mitigation measures were adopted: (1) ensure that the investigators had a minimum training in psychosocial intervention, (2) grant local authorities the right to exclude certain households deemed too socio-affectively vulnerable to be included in the study (which represented a negligible fraction), and (3) refer each participant to local resources if needed. Despite those measures, a low answer rate (15\%) is explained mainly by the limits of the recruitment process, through requests of participation initially sent to all systematically selected sample households. This filtered many defective mailing addresses. Only a dozen of denied permissions were received and are explained by strong solicitation of these communities from other scientific initiatives and government programs during the latest years (an emotional fatigue about the topic). The other main reason is the length of the survey, which dove into gathering personal experience rather than focusing on the quantity of respondents. Depending on the personal interest of the respondents, the survey could extend to $2 \mathrm{~h}$. The available field survey campaign being limited in time, this reduced the overall sample size.

\section{Data Processing}

Using STATA, descriptive statistics (Table 1) and the correlation matrix (Appendix 2) were calculated (by affected respondent, by gender, by stress level, etc.). Potential indicators (burden of expenditure, cost of preventive measures, contribution to the recovery effort, cost on health, financial difficulties, overall impact on physical and mental health, stress and sleep disturbance) were compared within different groups 
TABLE 1 | Sample descriptive statistics ( $n=101$ people).

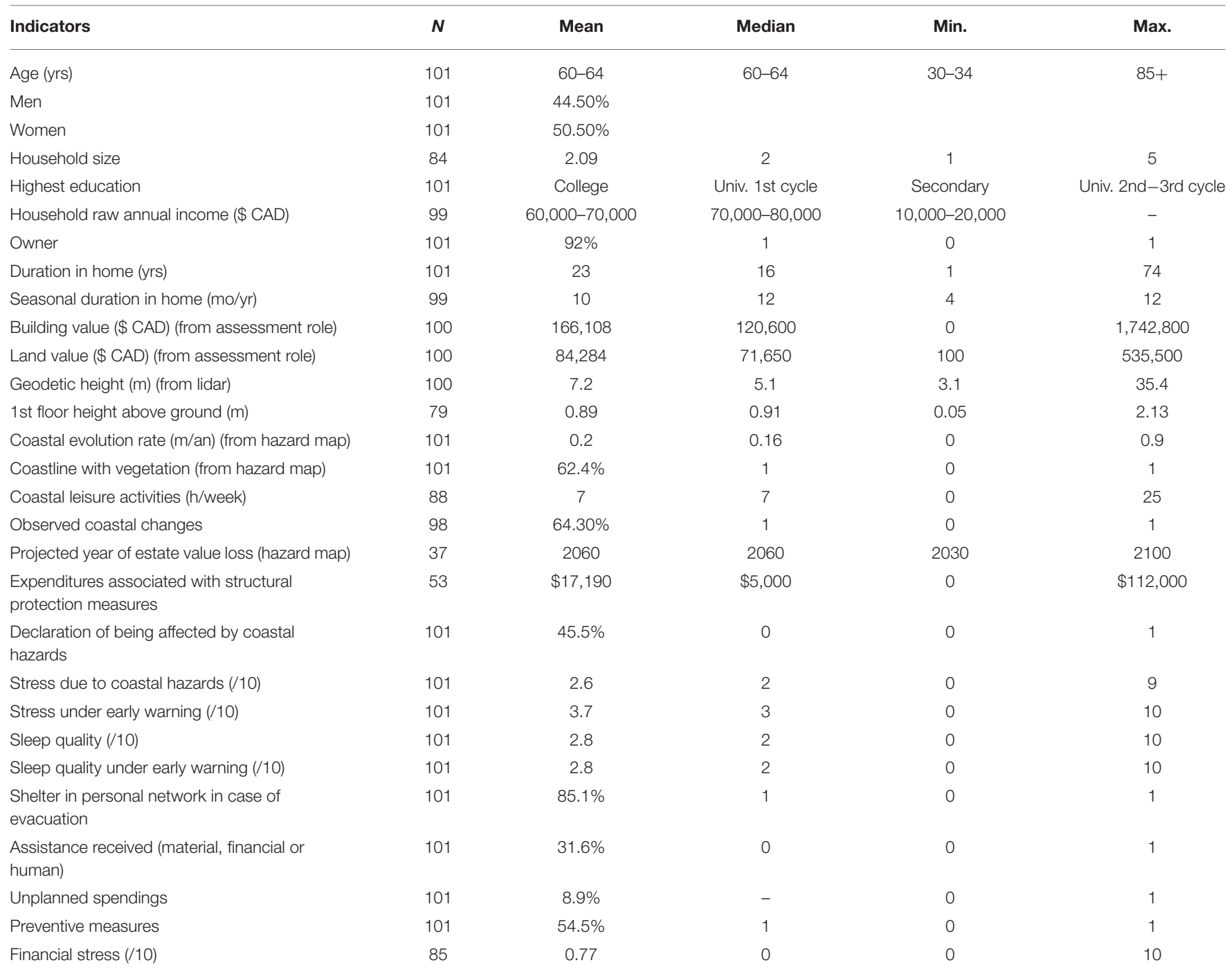

TABLE 2 | Type of major impacts on respondents $(n=101)$.

\begin{tabular}{|c|c|}
\hline Impacts & Percentage of sample \\
\hline Affected & $\begin{array}{l}46 \% \text { have declared being affected by coastal hazards (health, } \\
\text { financial or material losses) }\end{array}$ \\
\hline Productivity loss & $6 \%$ have missed days of work due to coastal hazards \\
\hline Material loss & $31 \%$ have experienced material loss \\
\hline $\begin{array}{l}\text { Health (physical or } \\
\text { mental) }\end{array}$ & $34 \%$ have experienced impacts on their health \\
\hline Physical health & $14 \%$ have experienced physical health impacts \\
\hline Mental health & $30 \%$ have experienced mental health impacts \\
\hline
\end{tabular}

(homeowner or not, affected person or not, isolated person or not, etc.) (Tables 2, 3). The Student's test (t-test) was used to analyze the difference in mean scores between affected and unaffected respondents for our different variables
(Table 3). Oaxaca (1973) developed a decomposition method for calculating the income gap between men and women. We used the same method to assess the difference between affected and unaffected respondents for our different variables. The empirical equation takes the following form: $\mathrm{Yi}=\mathrm{Xi}^{\prime} \beta$ ' $+\varepsilon \mathrm{i}$, where $\mathrm{Yi}$ represents the impact indicators variables such as stress level, stress level under early warning, sleep quality, sleep quality under early warning, absence from work, financial difficulty, supplementary health spending; Xi' represents explanatory variables such as the log of the respondent's income, age, sex, the adoption or not of preventive measures against climatic hazards, the degree of exposure to climatic hazards and the place of residence and, $\varepsilon$ i, the error term. The results of the decomposition for the deviations from the mean were reported in Table 4 (complete results available upon request). Finally, the preliminary data were validated with local stakeholders in December 2019, and the final results will be released once the circumstances concerning Covid-19 allow it. 
TABLE 3 | Descriptive and T-test comparison of affected and non-affected respondents ( $n=101)$.

\begin{tabular}{|c|c|c|c|c|c|c|c|}
\hline \multirow[t]{2}{*}{ Variables } & \multicolumn{2}{|c|}{ Non-affected respondents $(n=55)$} & \multicolumn{2}{|c|}{ Affected respondents ( $n=46$ ) } & \multirow[t]{2}{*}{ df } & \multirow[t]{2}{*}{$T$} & \multirow[t]{2}{*}{ Sig. } \\
\hline & Mean & SD & Mean & SD & & & \\
\hline Stress under early warning (/10) & 2.24 & 2.26 & 5.57 & 2.78 & -3.33 & -6.64 & 0.00 \\
\hline Sleep quality (/10) & 1.16 & 2.05 & 1.48 & 2.29 & -0.31 & 0.23 & 0.23 \\
\hline Financial difficulty $(0 / 10)$ & 0.16 & 0.78 & 1.44 & 2.47 & -1.28 & -3.27 & 0.00 \\
\hline Spendings on health goods and services $(y / n)$ & 0.02 & 0.13 & 0.40 & 0.50 & -0.38 & -5.48 & 0.00 \\
\hline
\end{tabular}

M, mean; SD, stand. Deviation; df, means differences; T, Student's t-test; Sig, significance level.

TABLE 4 | Indicators based on Blinder-Oaxaca decomposition statistics.

\begin{tabular}{lc}
\hline Impact indicators & $\begin{array}{c}\text { Predicted gap between affected and } \\
\text { unaffected respondents }\end{array}$ \\
\hline Stress level & $2.33^{\star \star \star}$ \\
Stress level under early warning & $3.54^{\star \star \star}$ \\
Sleep quality & 0.15 \\
Sleep quality under early warning & $2.39^{\star \star \star}$ \\
Absence from work & $0.10^{\star}$ \\
Financial difficulty & $1.27^{\star \star \star}$ \\
Supplementary health spendings & $0.38^{\star \star \star}$
\end{tabular}

${ }^{* \star *} p<0.01 ;{ }^{*} p<0.1$.

a The Oaxaca-Blinder decomposition here predicts a difference of 2.33 more stress for the affected individuals.

\section{RESULTS}

\section{Description of the Sample}

The sample of 101 people came almost equally from the two RCMs (49 from Rivière-du-Loup - RDL; 52 from La Mitis MS) (see Table 1). The majority of the respondents are elderly (median age 60-64 years), which contrasts with the median age of the total populations of MS and RDL, namely, 25-29 years according to the last census (Statistics Canada, 2016). There are more females $(50.5 \%)$ in the sample than males $(44.5 \%)$ or other/unreported (5.0\%). The median level of education is at the university undergraduate level. The gross household income of the sample is between CAD 70,000 and CAD 80,000, well above that of the overall population of the two RCMs (RDL: CAD 28,000; MS: CAD 14,000, in constant 2015 dollars) and above the Quebec average (CAD 59,000) (Statistics Canada, 2016). The average household size is 2.09 people. Most own their homes, $92 \%$ of which are fairly luxurious properties for the region (buildings with an average value of CAD 166,000 and land with an average value of CAD 84,000). Thus, apart from the elderly condition, the ability to cope is high.

The respondents have a long experience of coastal living (23 years in the same home) and spend an average of $7 \mathrm{~h}$ per week with coast-related leisure activities. Moreover, nearly $65 \%$ have observed changes to the coast. Sixty-three percent of the respondents' homes are located on a vegetated coastline, which indicates a certain stability, despite average erosion rates of 0.2 meter/year over the last few decades according to hazards maps (LDGIZC, 2017). At this rate, on average, buildings face a significant loss in projected value by 2060 . With regard to flooding, the ground floor of buildings is on average $0.89 \mathrm{~m}$ above the ground.

\section{General Impacts of Coastal Hazards}

Out of a total of 101 respondents, $46 \%$ said they were affected by coastal hazards, either by coastal erosion or coastal flooding, or both. The most important categories of impacts were, in order, material losses (31\%), mental health impacts (30\%), physical health impacts (14\%), and loss of productivity (6\%) (see Table 2). Comparing for affected and unaffected respondents in the sample, the prevalence of mental health and physical health appears higher for affected respondents: 50.0 and $23.9 \%$ against 13.5 and $5.8 \%$ for unaffected respondents (see Figure 1). Spatially, these responses are similar between the two regions, in both of which a majority of respondents affected by coastal hazards have experienced impacts on their health (physical or mental) (MS: 82\%; RDL: 69\%), and about a third of our sample (32\%) experienced material or productivity losses (see Table 2 ).

Thus, for a majority of people, being affected by coastal hazards compromises physical or mental health. These results also highlight the fact that a small fraction of the population (6$13 \%)$ may experience health impacts, without being exposed to the direct damage of hazards and simply by virtue of living in these communities. This indicates the strong dependence of the health status of coastal populations on hazard risk management.

\section{Indicators of Psychosocial Impacts of Coastal Hazards Stress and Sleep Disturbance}

Respondents rated their stress level and sleep disturbance on a scale of $0-10$ ( 10 being the worst health condition), both under normal conditions and during a storm warning.

With respect to stress, those unaffected by coastal hazards show a level ranging from 0 to 3 (median to 1), whereby the level of the warning does not significantly change the distribution (0-4, median to 2) (Figure 2). However, those 


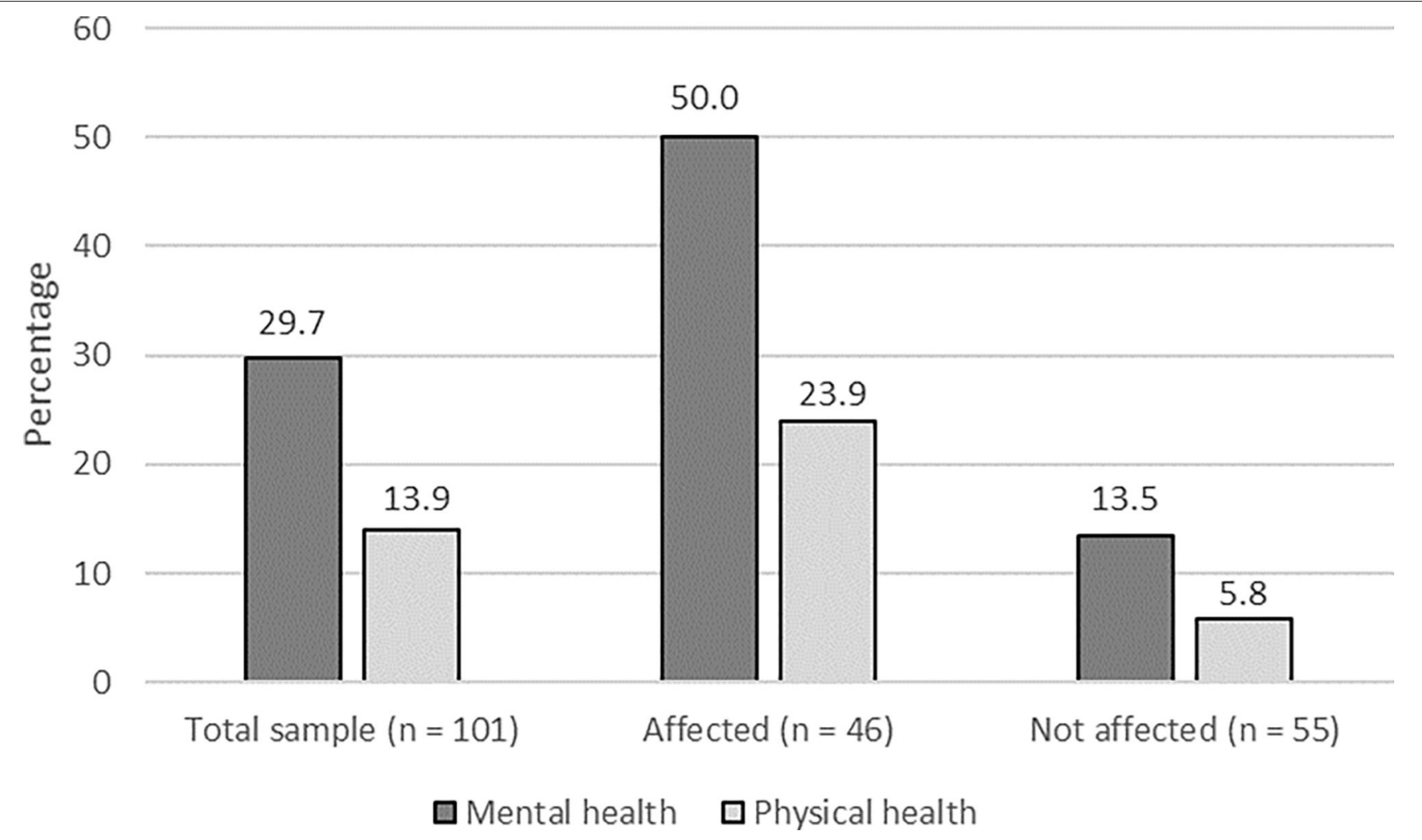

FIGURE 1 | Declaration of the impact of coastal hazards on the health of respondents according to their condition.

affected by coastal hazards are significantly more stressed, with a median of 4 in normal circumstances and rising to 6 during a warning (Figure 2, Table 3). The Oaxaca-Blinder decomposition predicts a difference of 2.33 more for the affected individuals, thus, affected people are 2.33 more stressed than unaffected respondents and this variation increases to 3.54 during a storm surge warning (Table 4).

In terms of sleep quality, those affected slept slightly worse than normal (average disturbance of 1.48 vs. 1.16), but the difference was most significant during a storm warning (disturbance of 4.13 vs. 2.21) (Figure 3, Table 3). Thus, the quality of sleep of affected respondents when a storm warning is issued is 2.39 poorer than that of unaffected respondents (Table 4). From the correlation matrix (Appendix 2), among all main socioeconomic descriptors and psychosocial impacts, only education was found correlated with sleep disturbance $(0.117$, significant at 0.1 level). Education is itself correlated with income (0.452). Since our sample is more educated than the general population, the existing correlation between education and sleep disturbance might overestimate the impact of coastal hazard compared to the general population. A hypothesis about a higher level of sensitivity to this impact among highly educated people is also plausible.

Thus, under normal circumstances, a person exposed to coastal hazards is more likely to be both stressed and to sleep less well, especially during a storm warning. Indeed, in the latter case the stress level is greater and the sleep twice more disturbed. This underscores the significant influence of coastal hazards on stress and sleep patterns. These two parameters are therefore sensitive and relevant indicators of health impacts.

\section{Effect of the Help Received}

Assistance (material, financial or human) is intended to protect victims of coastal hazards from stress. However, contrary to what would be expected, in the MS region, the level of stress is constant with or without assistance, and in the RDL region, the assistance received is even associated with a higher level of stress (see Figure 4). Thus, in neither of the two regions studied did the help received contribute significantly to reducing stress. Spatially, stress was lower in the RDL region than in the MS region (Figure 4). Thus, the level of stress increases spatially with the degree of exposure to coastal hazards.

\section{Effect of Social Isolation}

Interviewees assessed the assistance available to them in the context of evacuation following a storm warning. In the entire study area, only $15 \%$ of people said they could count on the presence of at least one relative or friend who would take them in in the event of an evacuation. This weak social network is associated with higher stress: during a storm warning, the level of stress for an isolated person is significantly higher $(\max 8 / 10$, 


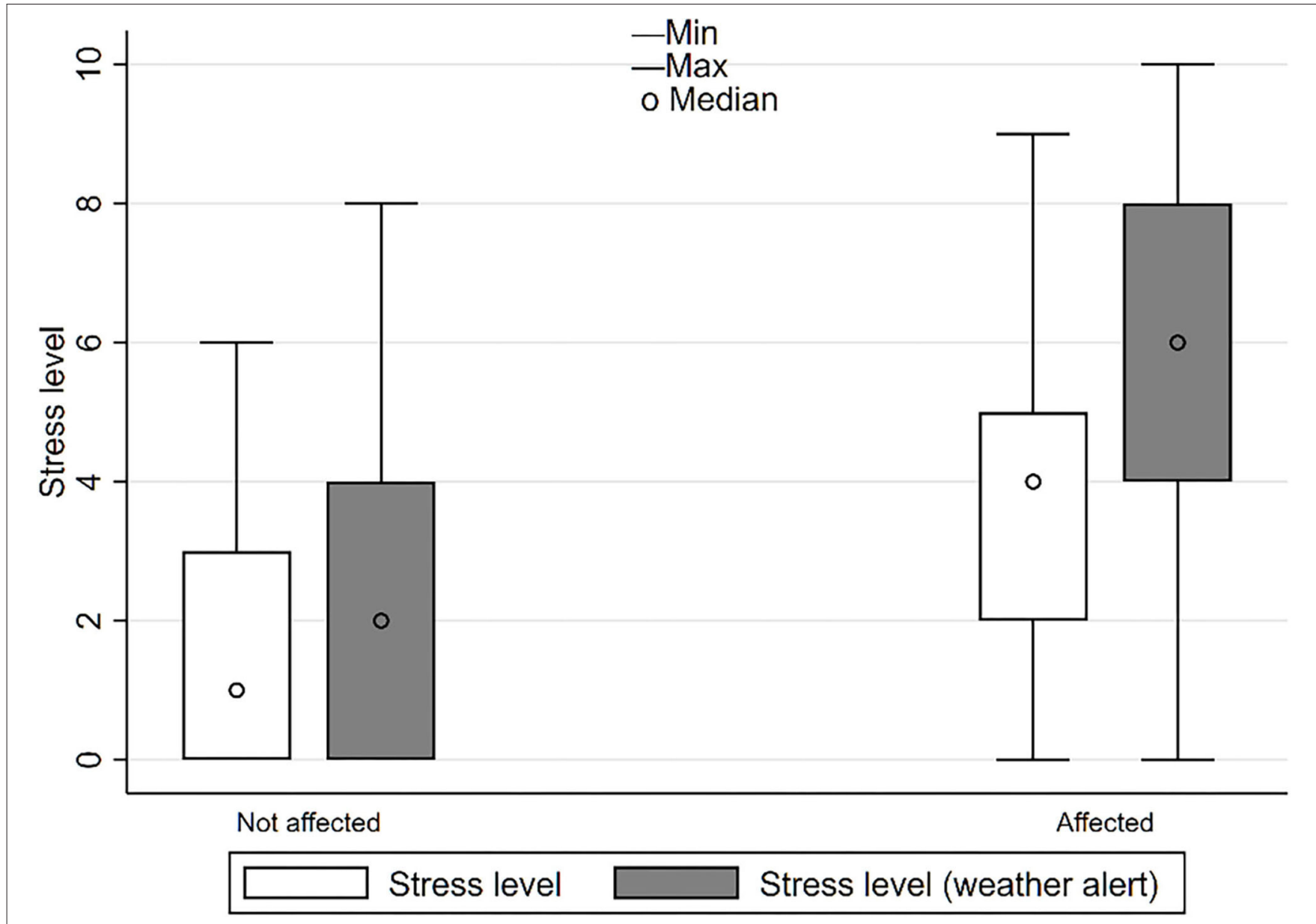

FIGURE 2 | Declaration of respondents' stress level according to their condition.

median 6/10) than for a person with a strong local social network ( $\max 5 / 10$, median 3/10) (see Figure 5).

Among the correlations with the socio-demographic variables, household size shows a similar effect. In fact, the smaller the household, the more negatively its mental health would be affected: there is thus a $12 \%$ greater risk for a household composed of no more than two people to be confronted with a mental health problem than for a household composed of more than two people ( $r=-0.14 ; 95 \%$ c.l.) (see Appendix 1). These two variables illustrate the importance of social capital in reducing the impact on mental health.

\section{Indicators of Economic Consequences Related to Psychosocial Impacts Loss of Productivity}

To measure the impacts of coastal hazards on productivity, respondents assessed their absence from work. To begin with, $11 \%$ of respondents affected by coastal hazards had to stop working for an indeterminate number of days as a result of a coastal event they experienced (Table 2). By measuring the effect of exposure on this variable, it appears that those affected by hazards have a $10 \%$ higher absence rate than unaffected respondents (Table 4). Exposure in our sample therefore leads to a significant increase in absenteeism from work, resulting in a loss of productivity for employers and possibly a drop in individual income. The number of days of work missed and the reasons (health, property damage, claim management, etc.) then allowed us to go further in interpreting the data.

\section{Expenses Related to Damage and Financial Hardship}

When asked about expenditures related to protection against hazard damage, 55\% said they had taken measures to protect their homes from coastal hazard damage (67\% among the affected subgroup; $44 \%$ among those projected to be affected by the hazard) (Table 1). Thus, the likelihood of experiencing financial difficulties is 1.27 higher for those affected compared to those not affected (Table 4). However, only $9 \%$ had faced unforeseen expenses to protect themselves against hazards. Coherently, those expenses placed only a fraction under financial difficulty (mean score of 0.77 over 10$)$. The cost of these measures varied widely: the minimum was a few hundreds, and the highest amount 


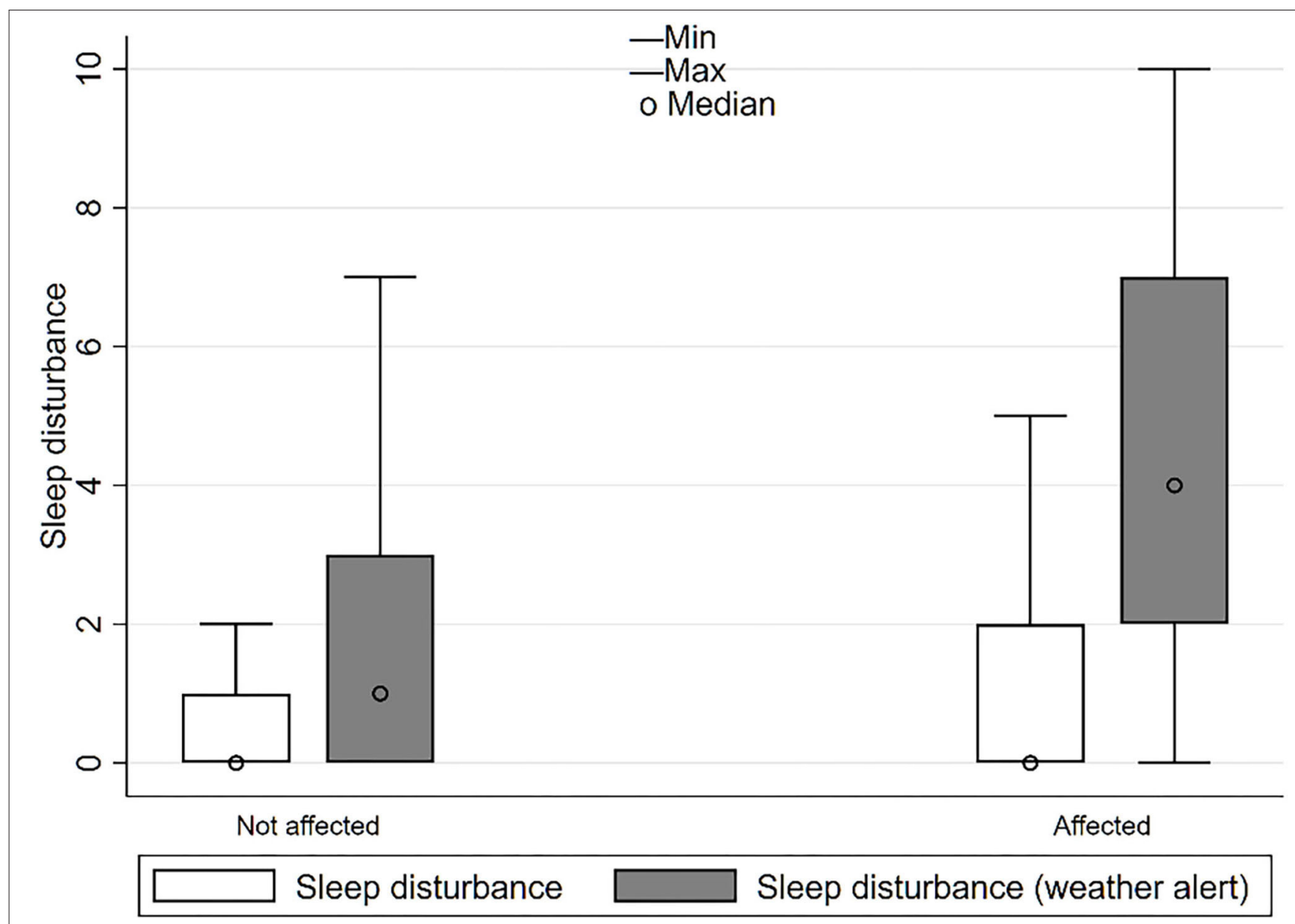

FIGURE 3 | Respondents' level of sleep disturbance according to their condition.

reported was $\$ 112,000 \mathrm{CAD}$. The small size of the subsample, however, did not allow for a measurement of the distribution. Avenues to be evaluated are: (1) spatial distribution: expenditures were generally more frequent and higher in MS than in RDL, a direct relationship with the magnitude of coastal hazard damage; (2) individual risk tolerance: the magnitude of expenditures appears to be associated not only with income level but also with stress level, underscoring, hence, a potential link with an individual's risk tolerance.

\section{Health-Related Expenses}

Respondents were asked to report on the impact of coastal hazards on their additional health care expenditures relative to average annual household expenditures. In our study, the additional annual health expenditures of a person affected by coastal hazards was of the order of magnitude of CAD 400 based on the limited data collected $(n<10)$. This monetary loss induced by health impacts could certainly be quantified more precisely, but is a realistic reference value according to the local project partners. Subjects who reported being affected by coastal hazards reported additional health expenses 38\% more than people who have not yet been harmed by the hazards (Table 4).

\section{DISCUSSION}

The objective of this study was to quantify the psychosocial impacts of coastal hazards (coastal erosion and coastal flooding) on shoreline populations in eastern Quebec, in order to integrate them into a CBA.

This study confirms that coastal erosion and coastal flooding generate significant impacts on mental health in coastal communities, particularly among those directly affected by these hazards. More specifically, it reveals the manifestation of psychosocial impacts in three main ways: a marked increase in stress, a marked sleep disturbance, and a particular sensitivity to storm warnings. These results are consistent with the role of secondary stressors in flood psychological impacts (Tempest et al., 2017), and the state of "panic" and "anxiety" in the face of the progression of erosion (Brisson and Richardson, 2009). Fear is primarily related to the anticipation of the total loss of one's home, which represents, more than just a material property, what protects one's personal well-being and identity (Dupuis and Thorns, 1998; Brisson and Richardson, 2009). As highlighted in previous disasters (e.g., DRSP, 2017), these variables of stress levels and sleep disturbance have definite potential for 


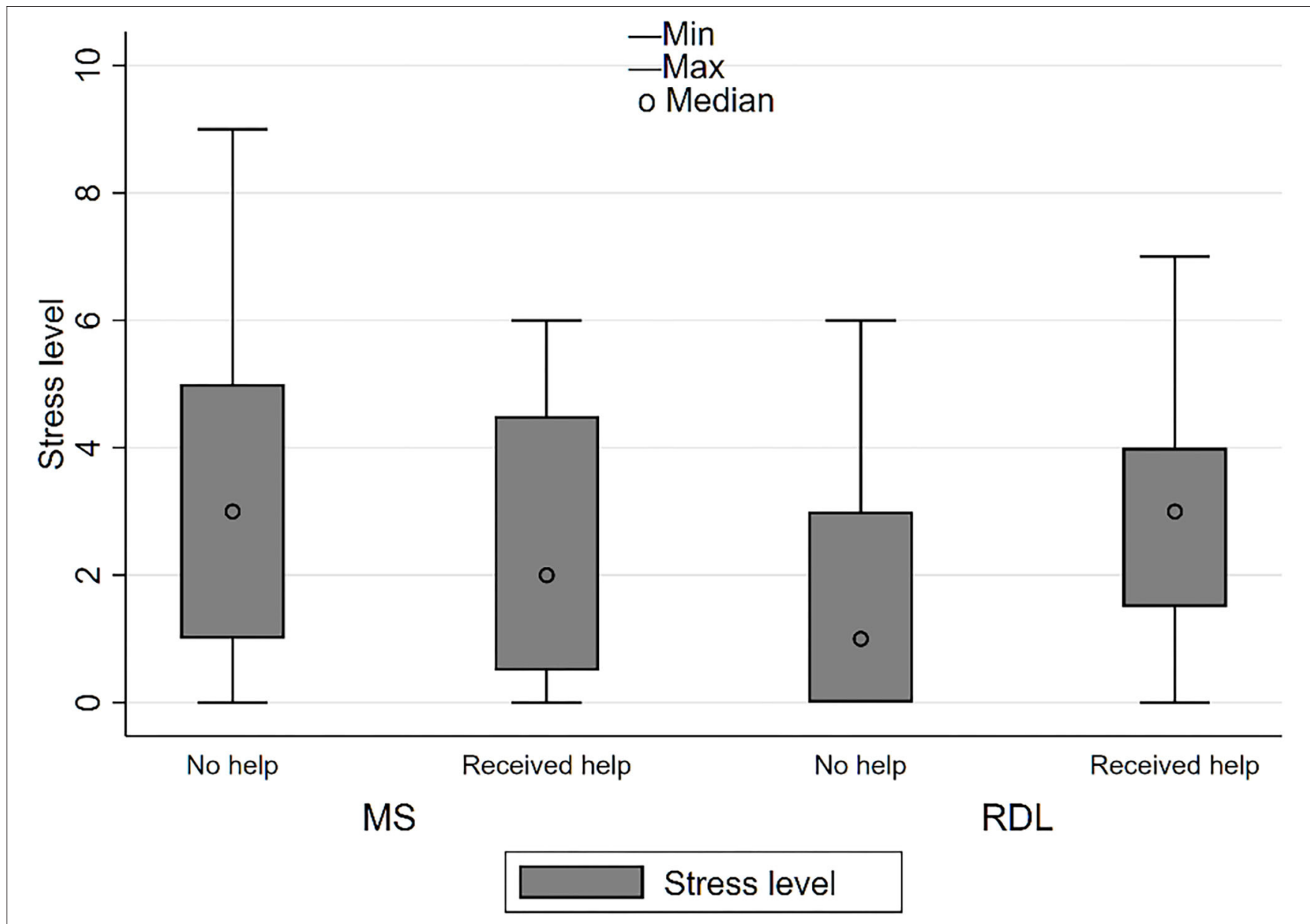

FIGURE 4 | Stress level according to the help received.

assessing the magnitude of psychosocial impacts. Further than the prevalence it provides for further assessments, this study points out to social capital and financial stress as key vulnerability determinants to be discussed.

\section{Role of Social Capital}

Among the determinants of these impacts, low social capital emerges as an aggravating factor in three ways. First, the smaller a household is, the more people report an effect on mental health: a household composed of no more than two people is $12 \%$ more likely to report effects of hazards on its mental health, compared to households composed of more than two people. Thus, not surprisingly, cohabitation encourages "bonding" between people in the same group (Almedom, 2005).

Second, higher stress is associated with a high degree of social isolation, as $15 \%$ of respondents would find themselves without a potential place to stay with a friend or relative during an evacuation. These proportions are of concern for the territory given that the need to find shelter elsewhere is one of the two factors, along with household income, most likely to contribute to the prevalence of psychosocial symptoms in households (Lamond et al., 2015). The factors involved in this increase in the victim's stress when receiving aid involve the mission of assistance services and the degree of novelty. First, local stakeholders confirm that the mission of government assistance services focus more on material or financial assistance; they do not succeed in reducing the emotional impacts on the people affected. This is why some municipalities (Sainte-Luce and Sainte-Flavie) have recently hired local coastal resilience officers who facilitate communications between the municipality and affected citizens and who offer individual support. Second, the novelty effect in the face of hazards affects stress: higher exposure in MS is associated with greater awareness and less association of the assistance received with the stress; whereas the low occurrence of hazards and the novelty of the consequences in the RDL region leads to greater stress, which the assistance received fails to alleviate. While there is thus a spatial variability to the help received, one thing is certain: receiving help services as currently designed does not significantly reduce stress levels, at least in the short term. Perceived social support is the only relevant indicator of the concept of social support (social network, perceived social support, and social support received) 


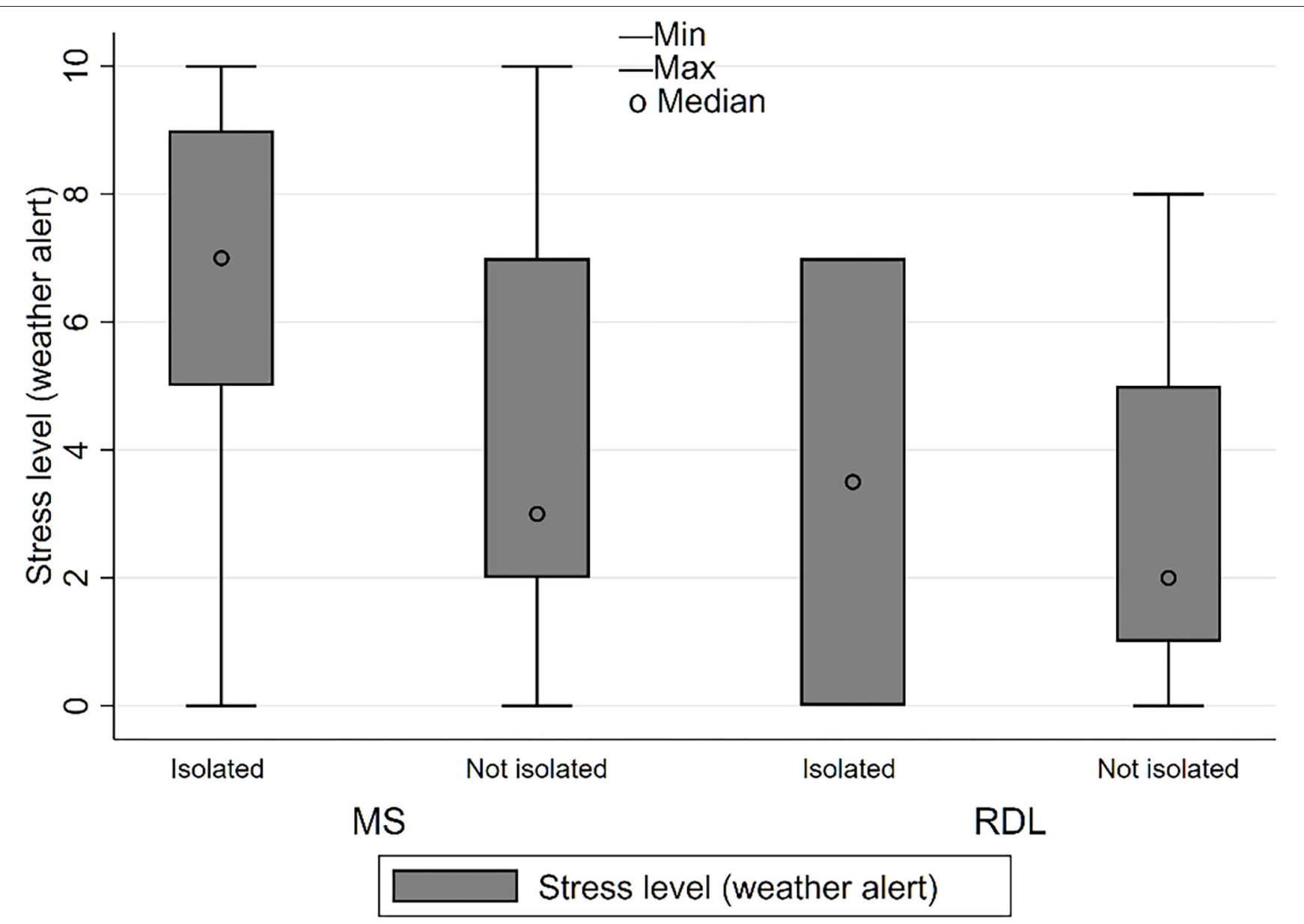

FIGURE 5 | Stress level according to the respondent's local social network.

because of its very significant protective effect on physical and mental health (Maltais, 2003). This confirms the weakness of "bridging" (social capital between groups) in the study site (Almedom, 2005) and the relevance of improving services in this regard to reduce secondary stressors.

Moreover, how long back in time one's "coastal identity" goes is both a vulnerability and a protection factor. On the one hand, advanced age-with a median of 65-69 years, compared to 25-29 years in the study area-is a main condition of individual vulnerability in the sample. It does, however, imply the advantage of experience: these respondents have been living at the same address for a long time (23 years on average), which affords them a high level of risk awareness (Boyer-Villemaire et al., 2014). Indeed, nearly $65 \%$ have observed changes in the coast and no $<46 \%$ of them are affected by coastal hazards. Finally, the age difference nevertheless suggests impacts on social capital: researchers have documented community tensions between generations as well as certain differences in conceptions of the common good and the distribution of compensation (Brisson and Richardson, 2009). Thus, having had a coastal identity for a long time has opposite effects. On the one hand, it reduces the novelty of hazards and enhances resilience, yet on the other hand, the advanced age, compared to the regional norm, leads to negative impacts, both on the individuals and on the community stress, by reinforcing a climate favoring tensions across generations.

In sum, this study reinforces the relevance of investing in measures to strengthen social capital, which is a protective factor for both individuals and communities in mitigating mental health impacts in the face of natural hazards, and points to the need to target approaches for community tensions.

\section{Financial Stress}

Furthermore, this study revealed the extent of financial stress that can impact those affected by coastal hazards. Within the sample, about one in two people took precautions against coastal hazards (55\%), with this behavior being more common among those affected (67\%) than those who do so in anticipation of a potential loss in value or use of a building (44\%).

In the study site, it is common knowledge that the protective measures chosen to date have been structural and individual (riprap, concrete walls, wooden walls). Out of a total of 101 
respondents, 55\% had spent money associated with structural protection measures. These measures are characterized by high costs and little flexibility to adapt to the increase in coastal hazards. This study provided only an order-of-magnitude estimate of the expenditures associated with these structural protection measures: the highest amount reported was $\$ 112,000$ $\mathrm{CAD}$. This must be put into perspective in relation to the average annual income of the sample of between CAD 70,000 and CAD 80,000. However, these expenses did not place them in financial difficulty $(0.8 / 10)$ (see Table 1 ). Those privileged conditions compared to regional averages are indeed associated with higher odds of exposure to flood (Graham et al., 2019). This is due to a persistent spatial pattern during the survey where first-line real estate values remained significantly higher than second-line, which is currently being self-corrected in market values after a dozen cases of public safety-based relocations, and coherently with theory expressing a trajectory of value loss in risky areas (e.g., McNamara and Keeler, 2013). However, these expenses can reach a significant ratio of annual income that is clearly sufficient to induce financial stress. Coherently, Graham et al. (2019) measured a greater effect of flood exposure compared to known predictors of mental health. In addition, the hazard projection adds to this stress because it implies an anticipated increase in expenditures over the next few decades. Coherently, the crucial role of property damage-observed or anticipatedon mental health has already been highlighted as a relevant indicator of flood impacts (Verger et al., 2003). To add to this, a recent study highlighted the role of insurance issues on mental health after flood in England: the lack of coverage increased probability of high severe stress, anxiety and ultimately PTSD (Mulchandani et al., 2019).

In the sample, the situation of financial hardship was low $(0.8 / 10)$ and because of this small magnitude, the correlation between expenses related to coastal protection and financial stress was only weak $\left(R^{2}=0.44\right.$, see Appendix 2). However, financial stress was significantly more prevalent among those who had already experienced impacts than those who did not (1.27 more frequent among those affected). In fact, the cost of investment prior to the damage (prevention) exerts less financial stress compared to the stress induced in people who are more exposed (e.g., more robust structures or more extensive protective work), to which are added post-storm repairs. Thus, the condition most vulnerable to financial stress occurred when the household made the effort to protect itself but nevertheless suffered damage that trigger an additional economic burden. This condition illustrates inefficient choices, also termed maladaptation, "an action that may lead to increased risk of adverse climate-related outcomes, increased vulnerability to climate change, or diminished welfare, now or in the future" (Agard et al., 2014). In the coastal context, it might be due to the underestimation of processes and its multiple factors, as well as spatio-temporal scales of evolution (Magnan et al., 2016). This corroborates the observations that repeatedly flooded individuals are more prone to depression compared with single events exposure (French et al., 2019). Thus, financial stress in our study constituted a tangible impact of coastal hazards, of limited magnitude, but which can be exacerbated by misplaced expenses related to coastal protection.

\section{Estimating the Economic Consequences of Health Impacts in the Context of Coastal Hazards}

This study identified two main economic impacts of coastal hazards on health. The first impact manifests itself as an additional $11 \%$ in absenteeism. It is true that difficulties linked to employment, work and finances are non-traumatic "stressors" (Bond, 2018). However, it is estimated that the economic impact of absenteeism in the workplace in Canada was 16.6 billions (Stewart, 2013). Coastal hazards thus contribute in part to this major cost to society, and the impact of this additional loss of productivity is of interest for CBA.

The second impact manifests itself in additional annual monetary expenditures on health products and services, representing a considerable challenge for coastal communities. Indeed, coastal hazards induce a reduction in quality of life related to stress (general stress, sleep disturbance or financial stress) (sections Role of Social Capital, Financial Stress). Financially, this study was only able to estimate the loss in a very general way: a person affected by coastal hazards was estimated to spend an additional CAD 400 annually on health products and services, representing a 38\% increase in health costs for those affected. Given that, in our sample, the impacts on mental health are of the order of $30 \%$ compared to $14 \%$ for physical health, it is plausible to assume that a good part of the expenditure is intended to address mental health impacts, especially since most physical health impacts are covered by health insurance, which is less the case for mental health. We can stipulate that sleep disruption is a precursor of anxiety, which generates direct costs in terms of health care delivered and indirect costs in terms of lost productivity of the affected subject. Lim et al. (2008) found that, for Canada in 2003, the total cost generated by mental disorders (including stress) was CAD 44,513 in 2020 (CAD 36,378 in 2008) per case for an individual diagnosed with a mental disorder in the healthcare system. In summary, the cost of the additional stress induced by coastal hazards for affected individuals (most of whom directly exposed to hazards, but also some simply living in a coastal community), would fall around CAD 400/adult person affected/year.

Admittedly, there are multiple biases in this estimate (small sample, indirect indicators, etc.). However, in a context of CBA, the importance of the psychosocial impacts justifies a consideration: professional diligence requires at the very least assessing the relevance of including this impact in the analysis with respect to the overall anticipated damages. Our study shows that the cost estimates are complex to quantify, as the consequences are not directly translatable into monetary terms. While our data has limitations, it is not excluded that the medical expenses cost could be negligible in the overall psychosocial costs, also comprising productivity loss, cost of stress and sleep deprivation. Therefore, using the cost of medical products or services alone to evaluate these effects may misrepresent (likely underestimate) the scope of the problem. Short and long term productivity losses and other health outcomes, such as losses in health-related quality of life from morbidity resulting from coastal hazards, should be also quantified (Lim et al., 2008). 
As corroborated by the informal intake of the survey and the coconstruction process, despite the small subsample size for respondents having declared additional health costs, this study reinforces the evidence that psychosocial impacts must weigh in coastal management decision making, but that there is an urgent need for further quantitative research at the frontier of epidemiology and health economics for being properly addressed in a context of CBA.

\section{Limits and Opportunities of the Research}

While sample size always remains an issue, the tendencies of the main indicators are significant enough and corroborated in the literature to be confident in the quantification of first-level indicators (stress, sleep). Furthermore, a small sample allowed for individual survey in person, which definitely enriched the interpretation of the results compared to a vast survey. That said, there are some mathematical limitations when decomposing a 100-sample to evaluate the responses across specific subsamples. Unfortunately, it affects the robustness of the results. Therefore, the economic indicators would merit a larger survey to narrow the scope of the estimate. At the spatial level, the study site included two non-adjacent territories, and some spatial variability in social impacts related to local exposure would be worth exploring. Overall, testing the indicators elsewhere would enhance their robustness.

The longitudinal population follow-up approach is recommended and would make it possible to address the perspective of age, lived experience, different health costs from one generation to the next, adaptation efforts as well as problems of social inequality (Delpla et al., 2015; Bohra et al., 2017). It would also make it possible to distinguish the evolution of past, present and future impacts and adaptation. In the case of the Lower Saint-Lawrence, we must avoid conducting an overload of research in certain communities. However, it should be noted that the vast majority of respondents appreciated our survey, which provided a forum for dialogue on their experiences going beyond the objectivity and inevitability of hazards. Finally, approaches for supporting communities faced with coastal hazards could be further explored, allowing for a closer longitudinal monitoring of the population, while strengthening the social capital.

The role of space appears very complex in the survey. First, the natural environment offers variable exposures to each hazard (erosion vs. flooding), which can also overlap. Their impact on the psychosocial indicators is null is our sample: all correlation scores between height or distance to the coast with declared psychosocial impact or declared stress due to hazards are ranging between 0.000 and 0.060 . This can be explained on the one hand by a high geodiversity (i.e., many different systems into a single $\mathrm{km}$ of coastal, for example low coasts: raised beaches, spit system or salt marshes) neighboring soft clif systems. This is typical of postglacial landscape and produces complex spatial patterns of hazards. Further multi-hazard mapping is required to clarify the dominant hazards and overlaps. Second, in this study, the human system is segregated into two single communities that have drastically different histories of hazard manifestation. In MS, the higher damages have triggered more media attention, raised awareness, gathered more resources (assistance received) from the authorities and even led to institutional transformations: managed retreat for a dozen households and hiring a special liaison agent between the citizens and the municipality. All those were absent from the second community. Consequently, that appears like a spatial effect coarser than geodiversity, heterogeneity between communities.

The absence of clear relationship between stress and exposure may reveal a mathematical bias that reduced the robustness of the results specifically about the exposure: some of the formerly firstline households relocated more inland were surveyed and their new coordinates may have introduced a bias in the relationship between distance and magnitude of impacts; unfortunately, their former coordinates should have been used but it is not possible to come back at this stage. However, this should not influence the prevalence and other variables studied. Further projects on the modeling of impacts based on sets of natural and human variables should provide more enlightenment on the multiscalar role of space in psychosocial impacts in the coastal domain.

\section{CONCLUSION}

The purpose of this study was to quantify psychosocial impacts for a cost-benefit study on a study site in two RCMs in the Lower Saint-Lawrence region of eastern Quebec, Canada. This main objective was achieved through a field survey of 101 respondents. The results illustrate the relevance of stress and sleep disturbance indicators for assessing the psychosocial impacts of coastal hazards in an economic analysis context. Unfortunately, the assistance received was not found to alleviate the stress, indeed, even worsening the stress, and a worrying level of social isolation was measured among those affected. Economic indicators related to psychosocial impacts translate into additional loss of productivity and financial hardship related to expenditures against damage. They contribute to the financial stress experienced by victims of coastal hazards and are exacerbated in the event of maladaptation. The estimate of additional health costs to populations would merit a broader economic investigation. Integration of indicators into coastal CBAs and longitudinal population-based monitoring is recommended.

\section{DATA AVAILABILITY STATEMENT}

The raw data supporting the conclusions of this article will be made available by the authors, without undue reservation.

\section{ETHICS STATEMENT}

The studies involving human participants were reviewed and approved by UQĀM certificate - CERPE FSH 3479. Written informed consent for participation was not required for this study in accordance with the national legislation and the institutional requirements. 


\section{AUTHOR CONTRIBUTIONS}

$\mathrm{UB}-\mathrm{V}$ the lead investigator, literature review, result analysis and interpretation, draft and final version, and strategic decisions. CK professional student investigator for data treatment. GL intern support for development of survey and data collection. ST for support for draft production. C-AG for scientific advising on economical science. All authors contributed to the article and approved the submitted version.

\section{FUNDING}

The PANACÉES project (\#580 004) is part of OURANOS Regional Climate Change and Adaptation Consortium scientific program. It was made possible with financial support from the Government of Canada and the Federation of Canadian Municipalities through the Partner Grants Program for a Climate Change Adaptation Project. This project was also funded by the Plan d'action 2013-2020 sur les changements climatiques of the Government of Quebec; by a contribution from regional

\section{REFERENCES}

Adams, R. E., and Boscarino, J. A. (2006). Predictors of PTSD and delayed PTSD after disaster: the impact of exposure and psychosocial resources. J. Nerv. Mental Dis. 194:485. doi: 10.1097/01.nmd.0000228503.95503.e9

Adger, W. N. (2001). Social Capital and Climate Change. Vol. 8. Norwich: Tyndall Centre Working Paper.

Adger, W. N. (2006). Vulnerability. Glob. Environ. Change 16, 268-281. doi: 10.1016/j.gloenvcha.2006.02.006

Agard, J. E., Schipper, L. F., Birkmann, J., Campos, M., Dubeux, C., Nojiri, Y., et al. (2014). Annex II: Glossary. IPCC Climate Change AR5 - Working group II, 1757-1758.

Alderman, K., Turner, L. R., and Tong, S. (2012). Floods and human health: a systematic review. Environ. Int. 47, 37-47. doi: 10.1016/j.envint.2012.06.003

Aldrich, D. P., and Meyer, M. A. (2015). Social capital and community resilience. Am. Behav. Sci. 59, 254-269. doi: 10.1177/0002764214550299

Almedom, A. M. (2005). Social capital and mental health: an interdisciplinary review of primary evidence. Soc. Sci. Med. 61, 943-964. doi: 10.1016/j.socscimed.2004.12.025

Bernatchez, P., Dugas, S., Fraser, C., and Da Silva, L. (2015). Évaluation économique des impacts potentiels de l'érosion des côtes du Québec maritime dans un contexte de changements climatiques. Rimouski, QC: Laboratoire de dynamique et de gestion intégrée des zones côtières, Université du Québec à Rimouski, Rapport de recherche remis à Ouranos, 60. Available online at: https://ouranos.ca/wpcontent/uploads/RapportBernatchez2015_FR.pdf

Bernatchez, P., Fraser, C., Lefaivre, D., and Dugas, S. (2011). Integrating anthropogenic factors, geomorphological indicators and local knowledge in the analysis of coastal flooding and erosion hazards. Ocean Coast. Manag. 54, 621-632. doi: 10.1016/j.ocecoaman.2011.06.001

Bernatchez, P., and Quintin, C. (2016). Potentiel de migration des écosystèmes côtiers meubles québécois de l'estuaire et du golfe du Saint-Laurent dans le contexte de la hausse appréhendée du niveau de la mer. Le Naturaliste Canadien 140, 91-104. doi: 10.7202/1036507ar

Bohra, T., Benmarhinia, T., McKinnon, B., and Kaufman, J. S. (2017). Decomposing educational inequalities in child mortality: a temporal trend analysis of access to water and sanitation in Peru. Am. J. Trop. Med. Hygiene 96, 57-64. doi: 10.4269/ajtmh.15-0745

Bolin, R. (1985). "Disaster characteristics and psychosocial impacts," in Disasters and Mental Health: Selected Contemporary Perspectives, eds B. J. Sowder (Washington, DC: Department of Health and Human Services), 3-28. county municipalities and participating municipalities; and also received support from Réseau sur les inondations inter-sectoriel du Québec (RIISQ).

\section{ACKNOWLEDGMENTS}

A sincere thanks to Mélissa Généreux, M.D., Chantal Quintin, M.Sc. Laurent Da Silva, M.Sc., M.Env., Nathalie Bleau, M.ATDR. and the Analysis in Adaptation Science Team at Ouranos for advising on questionnaire and preliminary results. We also acknowledge Marie Raphoz and Philippe Gachon, UQAMGeography and RIISQ and their support team for their contribution to initial literature review and infrastructure supporting this project.

\section{SUPPLEMENTARY MATERIAL}

The Supplementary Material for this article can be found online at: https://www.frontiersin.org/articles/10.3389/fclim. 2021.591416/full\#supplementary-material

Bond, S. (2018). Les sinistres majeurs comme événements traumatiques : une introduction - Partie 2, Montreal, QC: Département de psychologie, UQÀM, p. 39.

Bourdieu, P. (1980). Le capital social: notes provisoires. Actes de la recherche en sciences sociales 31, 2-3. doi: 10.3406/arss.1980.2077

Boyer-Villemaire, U., Bernatchez, P., Benavente, J., and Cooper, J. A. G. (2014). Quantifying community's functional awareness of coastal changes and hazards from citizen perception analysis in Canada, UK and Spain. Ocean Coast. Manag. 93, 106-120. doi: 10.1016/j.ocecoaman.2014.03.016

Boyer-Villemaire, U., Savard, J.-P., and Roy, P. (2016). Évaluation des niveaux d'eau extrêmes causant des dommages de submersion en zone côtière au Québec. Montréal: Ouranos, p. 30.

Brisson, G., and Lessard, L. (2018). Project: Améliorer la réponse aux besoins psychosociaux des individus et communautés touchés par des aléas climatiques dans les régions de l'est du Québec, UQAR. Available online at: https:// www.qualaxia.org/wp-content/uploads/2018-mars_presentation-brisson-etlessard.pdf (accessed June 18, 2021).

Brisson, G., and Richardson, M. (2009). Perception de l'érosion des berges de la CôteNord et perspectives de santé publique. Baie-Comeau: Agence de la santé et des services sociaux de la Côte-Nord, p. 47.

Buffin-Bélanger, T., Biron, P. M., Larocque, M., Demers, S., Olsen, T., Choné, G., et al. (2015). Freedom space for rivers: an economically viable river management concept in a changing climate. Geomorphology. 251, 137-148. doi: 10.1016/j.geomorph.2015.05.013

Chan, E. Y. Y., Huang, Z., Lam, H. C. Y., Wong, C. K. P., and Zou, Q. (2019). Health vulnerability index for disaster risk reduction: application in belt and road initiative (BRI) region. Int. J. Environ. Res. Public Health 16:380. doi: 10.3390/ijerph16030380

Chaskin, R. J. (2008). Resilience, community, and resilient communities: conditioning contexts and collective action. Child Care Practice 14, 65-74. doi: 10.1080/13575270701733724

Circé, M., Da Silva, L., Mercier, X., Duff, G., Boyer-Villemaire, U., Corbeil, S., et al. (2016). Analyse coûts-avantages des options d'adaptation en zone côtière à Carleton-sur-Mer. Ouranos: Montréal, p. 169.

CRED (2018). The human cost of natural disasters 2015, A global perspective. Louvain-la-Neuve: Université Catholique de Louvain et Institute of Health and Society (IRSS), Centre for Research on the Epidemiology of Disasters, p. 58.

Delpla, I., Bnmarhnia, T., Lebel, A., Levallois, P., and Rodriguez, M. J. (2015). Investigating social inequalities in exposure to drinking water contaminants in rural areas. Environ. Pollut. 207, 88-96. doi: 10.1016/j.envpol.2015.08.046 
DRSP (2017). Press release, June 6, 2017, Le Directeur de santé publique de Montréal présente les principaux constats de l'enquête santé réalisée auprès des victimes des inondations, Preliminary report. Montréal: Direction régionale de santé publique.

Dückers, M. L., Witteveen, A. B., Bisson, J. I., and Olff, M. (2017). The association between disaster vulnerability and post-disaster psychosocial service delivery across Europe. Adm. Policy Mental Health. 44, 470-479. doi: 10.1007/s10488-015-0671-8

Dupuis, A., and Thorns, D. C. (1998). Home, home ownership and the search for ontological security. Sociol. Rev. 46, 24-47. doi: 10.1111/1467-954X.00088

Etkin, D., Jaffit, E., Joe, P., Jones, B., Koshida, G., Grace, L., et al. (2010). Canadians at Risk: Our Exposure to Natural Hazards Canadian Assessment of Natural Hazards Project. Toronto, ON: Institute for Catastrophic Loss Reduction, ICLR Research Paper Series, p. 235.

Ford, J. D., Pearce, T., McDowell, G., Berrang-Ford, L., Sayles, J. S., and Belfer, E. (2018). Vulnerability and its discontents: the past, present, and future of climate change vulnerability research. Clim. Change 151, 189-203. doi: $10.1007 /$ s10584-018-2304-1

French, C. E., Waite, T. D., Armstrong, B., Rubin, G. J., Beck, C. R., and Oliver, I. (2019). Impact of repeat flooding on mental health and health-related quality of life: a cross-sectional analysis of the English National Study of Flooding and Health. BMJ Open 9:e031562. doi: 10.1136/bmjopen-2019-031562

Füssel, H. M. (2007). Vulnerability: a generally applicable conceptual framework for climate change research. Global Environ. Change 17, 155-167. doi: 10.1016/j.gloenvcha.2006.05.002

Genereux, M., Maltais, D., and Gachon, P. (2017). Project: Une évaluation sociosanitaire des inondations 2017, un an plus tard: Optimiser les services de santé et l'intervention psychosociale post-désastre visant la résilience des collectivités aux extremes hydrométéorologiques. Université de Sherbrooke. Available online at: http://www.monclimatmasante.qc.ca/Data/Sites/1/cp/26. 3.5_Inondations2019-USherbrooke_Fiche_projet_2020-02-14_FINALE.pdf (accessed June 18, 2021).

Généreux, M., Maltais, D., Petit, G., and Roy, M. (2019). Monitoring adverse psychosocial outcomes one and two years after the Lac-Mégantic train derailment tragedy (Eastern Townships, Quebec, Canada). Prehosp. Disaster Med. 34, 251-259. doi: 10.1017/S1049023X19004321

Gill, D. A., Ritchie, L. A., and Picou, J. S. (2016). Sociocultural and psychosocial impacts of the Exxon Valdez oil spill: twenty-four years of research in Cordova, Alaska. Extractive Indus. Soc. 3, 1105-1116. doi: 10.1016/j.exis.2016.09.004

Graham, H., White, P., Cotton, J., and McManus, S. (2019). Flood-and weatherdamaged homes and mental health: an analysis using England's mental health survey. Int. J. Environ. Res. Public Health. 16:3256. doi: 10.3390/ijerph16183256

Greene, G., Paranjothy, S., and Palmer, S. R. (2015). Resilience and vulnerability to the psychological harm from flooding: the role of social cohesion. Am. J. Public Health 105, 1792-1795. doi: 10.2105/AJPH.2015.302709

Han, G., Ma, Z., Chen, N., Thomson, R., and Slangen, A. (2015). Changes in mean relative sea level around Canada in the twentieth and twenty-first centuries. Atmosphere Ocean. 53, 452-463. doi: 10.1080/07055900.2015.1057100

Ibrahim, D. (2016). Les expériences des Canadiens liées aux situations d'urgence et aux catastrophes, 2014. Ottawa, ON: Centre canadien de la statistique juridique.

INSPQ (2015). Inondations : état de situation des responsabilités et pratiques en santé environnementale. Québec City, QC: Direction de la santé environnementale et de la toxicologie. Institut national de santé publique du Québec.

IPCC (2012). Managing the Risks of Extreme Events and Disasters to Advance Climate Change Adaptation. A Special Report of Working Groups I and II of the Intergovernmental Panel on Climate Change. Cambridge; New York, NY: Cambridge University Press, p. 582.

James, T. S., Henton, J. A., Leonard, L. J., Darlington, A., Forbes, D. L., and Craymer, M. (2014). Relative Sea-Level Projections in Canada and the Adjacent Mainland United States. Ottawa, ON: Geological Survey of Canada. p. 72.

Johal, S., and Mounsey, Z. (2016). A research-based primer on the potential psychosocial impacts of flooding. Disaster Prevent. Manag. 25, 104-110. doi: 10.1108/DPM-09-2015-0206

Koohzare, A., Vaníček, P., and Santos, M. (2008). Pattern of recent vertical crustal movements in Canada. J. Geodynam. 45, 133-145. doi: 10.1016/j.jog.2007.08.001
Korman, M. B., Goldberg, L., Klein, C., Khanjani, M., Cox, G., Fila, E., et al. (2019). Code orange: a systematic review of psychosocial disaster response. Prehosp. Disaster Med. 34, s69-s70. doi: 10.1017/S1049023X190 01511

Kulig, J. C., and Dabravolskaj, J. (2020). The psychosocial impacts of wildland fires on children, adolescents and family functioning: a scoping review. Int. J. Wildland Fire 29, 93-103. doi: 10.1071/WF18063

Lamond, J. E., Joseph, R., and Proverbs, D. (2015). An exploration of factors affecting the long term psychological impact and deterioration of mental health in flooded households. Environ. Res. 140, 325-334. doi: 10.1016/j.envres.2015.04.008

LDGIZC (2017). Laboratoire de dynamique et de gestion intégrée des zones côtières de l'Université du Québec à Rimouski (2017). Available online at: https://sigec. cartovista.com/Web (accessed February 20, 2020).

Leon, G. R. (2004). Overview of the psychosocial impact of disasters. Prehosp. Disaster Med. 19, 4-9. doi: 10.1017/S1049023X00001424

Lim, K. L., Jacobs, P., Ohinmaa, A., Schopflocher, D., and Dewa, C. S. (2008). A new population-based measure of the economic burden of mental illness in Canada. Chronic Dis. Can. 28, 92-98. doi: 10.24095/hpcdp.28.3.02

Magnan, A. K., Schipper, E. L. F., Burkett, M., Bharwani, S., Burton, I., Eriksen, S., et al. (2016). Addressing the risk of maladaptation to climate change. Wiley Interdiscip. Rev. Clim. Change 7, 646-665. doi: 10.1002/wcc.409

Maltais, D. (2003). Catastrophe en milieu rural. Chicoutimi, Québec: Les Éditions JCL Inc., p. 322.

Maltais, D., and Gauthier, S. (2013). Le contexte social des catastrophes naturelles ou l'importance de tenir compte du concept de vulnérabilité dans la prévention et la gestion des catastrophes, dans A. De Serres (dir.), La gestion des risques majeurs : la résilience organisationnelle - Apprendre à être surpris. Québec, éditions Yvon Blais, collection FidRisk, 345-365.

Maltais, D., Pouliot, È., Lansard, A. L., Fortin, G., and Petit, G. (2019). Les répercussions du déraillement du train de Lac-Mégantic sur la santé psychosociale d'élèves du primaire. Enfance en difficulté 6, 5-36. doi: 10.7202/1066577ar

Maltais, D., Robichaud, S., and Simard, A. (2001). Sinistres et intervenants. Chicoutimi, Québec: Les Éditions JCL Inc., p. 275.

McNamara, D. E., and Keeler, A. (2013). A coupled physical and economic model of the response of coastal real estate to climate risk. Nat. Clim. Change 3, 559-562. doi: 10.1038/nclimate1826

Meewisse, M.-L., Nijdam, M. J., de Vries, G. J., Gersons, B. P., Kleber, R. J., van der Velden, P. G., et al. (2005). Disaster-related posttraumatic stress symptoms and sustained attention: Evaluation of depressive symptomatology and sleep disturbances as mediators. J. Traumatic Stress 18, 299-302. doi: $10.1002 /$ jts.20037

Midorikawa, S., Tanigawa, K., Suzuki, S., and Ohtsuru, A. (2017). Psychosocial issues related to thyroid examination after a radiation disaster. Asia Pacific J. Public Health 29 (2_suppl), 63S-73S. doi: 10.1177/1010539516686164

Ministère de la Sécurité Publique (2019). Plan national de sécurité civile, ministère de la Sécurité publique, gouvernement du Québec. Available online at: https:// www.securitepublique.gouv.qc.ca/securite-civile/plan-national.html (accessed June 18, 2021).

Mulchandani, R., Smith, M., Armstrong, B., Beck, C. R., and Oliver, I. (2019). Effect of insurance-related factors on the association between flooding and mental health outcomes. Int. J. Environ. Res. Public Health 16:1174. doi: $10.3390 /$ ijerph16071174

Natural Resources Canada (2016). Canada's Marine Coasts in a Changing Climate. Ottawa, ON: Government of Canada, p. 280.

Norris, F. H., Friedman, M. J., Watson, P. J., Byrne, C. M., Diaz, E., and Kaniasty, K. (2002). 60,000 disaster victims speak: part $i$, an empirical review of the empirical literature, 1981-2001. Psychiatry 65, 207-239. doi: 10.1521/psyc.65.3.207.20173

Oaxaca, R. (1973). Male-female wage differentials in urban labor markets. Int. Econ. Rev. 14, 693-709. doi: 10.2307/2525981

Pelling, M., and High, C. (2005). Understanding adaptation: what can social capital offer assessments of adaptive capacity? Global Environ. Change 15, 308-319. doi: 10.1016/j.gloenvcha.2005.02.001

Penning-Rowsell, E., Priest, S., Parker, D., Morris, J., Tunstall, S., Viavattene, C., et al. (2013). Flood and Coastal Erosion Risk Management. London: Routledge, 448. 
Priebe, S., Marchi, F., Bini, L., Flego, M., Costa, A., and Galeazzi, G. (2011). Mental disorders, psychological symptoms and quality of life 8 years after an earthquake : findings from a community sample in Italy. Soc. Psychiatry Psychiatre Epidemiol. 46, 615-621. doi: 10.1007/s00127-010-0227-x

Rapaport, C., Hornik-Lurie, T., Cohen, O., Lahad, M., Leykin, D., and Aharonson-Daniel, L. (2018). The relationship between community type and community resilience. Int. J. Disaster Risk Reduct. 31, 470-477. doi: $10.1016 /$ j.ijdrr.2018.05.020

Reyes, G., and Elhai, J. D. (2004). Psychosocial interventions in the early phases of disasters. Psychother. Theory Res. Pract. Training 41:399. doi: 10.1037/0033-3204.41.4.399

Sartorius, N. (2003). Social capital and mental health. Curr. Opin. Psychiatry 16, S101-S105. doi: 10.1097/00001504-200304002-00015

Smit, B., and Wandel, J. (2006). Adaptation, adaptive capacity and vulnerability. Global Environ. Change 16, 282-292. doi: 10.1016/j.gloenvcha.2006.03.008

Statistics Canada (2016). Census Profile, 2016 Census. Available online at: https:// www12.statcan.gc.ca/census-recensement $/ 2016 / \mathrm{dp}-\mathrm{pd} /$ prof/index.cfm?Lang= E (accessed February 01, 2021).

Stewart, N. (2013). Missing in Action: Absenteeism Trends in Canadian Organizations. The Conference Board of Canada, p. 11. Available online at: $\quad$ https://www.conferenceboard.ca/e-library/abstract.aspx?did=5780\& AspxAutoDetectCookieSupport=1 (accessed December 23, 2020).

Tempest, E. L., English National Study on Flooding and Health Study Group, Carter, B., Beck, C. R., Rubin, G. J. (2017). Secondary stressors are associated with probable psychological morbidity after flooding: a cross-sectional analysis. Eur. J. Public Health 27, 1042-1047. doi: 10.1093/eurpub/ckx182

Turner, B. L., Kasperson, R. E., Matson, P. A., McCarthy, J. J., Corell, R. W., Christensen, L., et al. (2003). A framework for vulnerability analysis in sustainability science. Proc. Natl. Acad. Sci. 100, 8074-8079. doi: $10.1073 /$ pnas. 1231335100
UNISDR (2015). Cadre daction de Sendai pour la réduction des risques de catastrophes 2015-2030, Consulted February 1st, 2017. Organisation des Nations unies pour la réduction des risques de catastrophes. Available online at: www.unisdr.org/files/43291_frenchsendaiframeworkfordisasterris. pdf (accessed Fabruary 1, 2017).

Urgence Québec (2017). Inondations printanières 2017: Le gouvernement du Québec confirme le retrait officiel des Forces armées canadiennes, Sécurité publique Québec. Available online at: https://www.securitepublique.gouv.qc. $\mathrm{ca} /$ ministere/sallepresse/communiques/detail/13780.html (accessed July 28, 2020).

Verger, P., Rotily, M., Hunault, C., Brenot, J., Baruffol, E., and Bard, D. (2003). Assessment of exposure to a flood disaster in a mental-health study. J. Exposure Sci. Environ. Epidemiol. 13, 436-442. doi: 10.1038/sj.jea.7500290

Watts, M. J., and Bolhe, G. (2013). Hunger, famine, and the space of vulnerability. Geojournal 30, 117-125. doi: 10.1007/B.F.00808128

WMO (2014). Atlas of Mortality and Economic Losses from Weather, Climate and Water Extremes (1970-2012), WMO - no 1123. Geneva: World Meteorological Organization. p. 48.

Conflict of Interest: The authors declare that the research was conducted in the absence of any commercial or financial relationships that could be construed as a potential conflict of interest.

Copyright $\odot 2021$ Boyer-Villemaire, Kanli, Ledoux, Gosselin and Templier. This is an open-access article distributed under the terms of the Creative Commons Attribution License (CC BY). The use, distribution or reproduction in other forums is permitted, provided the original author(s) and the copyright owner(s) are credited and that the original publication in this journal is cited, in accordance with accepted academic practice. No use, distribution or reproduction is permitted which does not comply with these terms. 